Research Article

\title{
Relation of Wnt Signaling Pathway Inhibitors (Sclerostin and Dickkopf-1) to Left Ventricular Mass Index in Maintenance Hemodialysis Patients
}

\author{
Ahmed Bahie, ${ }^{1}$ Mohamed M. Abdalbary, ${ }^{1}$ Dalia Younis El-Sayed, ${ }^{1}$ Rasha Elzehery, \\ Ghada El-Said, ${ }^{1}$ Ghada El-Kannishy, ${ }^{1}$ and Ahmed M. Abd El Wahab ${ }^{1}{ }^{1}$ \\ ${ }^{1}$ Internal Medicine Department, Mansoura Nephrology and Dialysis Unit (MNDU), Mansoura Faculty of Medicine, \\ Mansoura, Egypt \\ ${ }^{2}$ Department of Clinical Pathology, Mansoura University, Mansoura, Egypt
}

Correspondence should be addressed to Ahmed M. Abd El Wahab; drabdoo34@gmail.com

Received 6 June 2021; Revised 3 August 2021; Accepted 11 September 2021; Published 23 September 2021

Academic Editor: Martin Sedlacek

Copyright ( 2021 Ahmed Bahie et al. This is an open access article distributed under the Creative Commons Attribution License, which permits unrestricted use, distribution, and reproduction in any medium, provided the original work is properly cited.

Background. Left ventricular hypertrophy (LVH) is common in hemodialysis (HD) patients. It predicts poor prognosis. Several inhibitors regulate Wnt canonical pathways like Dickkopf-related protein-1 (Dkk-1) and sclerostin. Objectives. To investigate the relationship between serum sclerostin, Dkk-1, left ventricular mass (LVM), and LVM index (LVMI) in HD patients. Methods. This is a cross-sectional study including $65 \mathrm{HD}$ patients in our HD unit. Patients were divided into two groups according to LVMI (group 1 with $\mathrm{LVMI}<125 \mathrm{gm} / \mathrm{m}^{2}(N=29)$ and group 2 with $\mathrm{LVMI}>125 \mathrm{gm} / \mathrm{m}^{2}(N=36)$ ). Echocardiographic evaluation of the LVM, aortic, and mitral valves calcification (AVC and MVC) was done. Serum levels of sclerostin and Dkk-1 and patients' clinical and biochemical data were recorded. Results. Group 2 showed significantly higher age, blood pressure, AVC, and MVC and significantly lower hemoglobin, sclerostin, and Dkk-1 levels. LVM and LVMI had a significant linear negative correlation to both serum sclerostin and Dkk-1 $(r=-0.329$ and $-0.257, P=0.01$ and 0.046 for LVM; $r=-0.427$ and $-0.324, P=0.001$ and 0.012 for LVMI, resp.). Serum Dkk-1 was an independent negative indicator for LVM and LVMI in multiple regression analyses $(P=0.003$ and 0.041 with $95 \% \mathrm{CI}=-0.963$ to -0.204 and -0.478 to -0.010 , resp.). Conclusion. Serum sclerostin and Dkk- 1 were significantly lower in HD patients with increased LVMI $>125 \mathrm{gm} / \mathrm{m}^{2}$, and both had a significant linear negative correlation with LVM and LVMI. Dkk-1 was a significant negative independent indicator for LVM and LVMI in HD patients.

\section{Introduction}

Left ventricular hypertrophy (LVH) is common structural remodeling in patients with end-stage renal disease, and its presence predicts a poor prognosis [1]. Echocardiographic diagnosis of LVH is based on cutoff values developed from formula formed from population-based studies which indexed the left ventricular mass (LVM) to the body surface area (BSA) [2].

$\mathrm{Wnt} / \beta$-catenin signaling pathway is an essential positive regulated signaling network for cardiovascular diseases [3]. $\beta$-Catenin increases the expression of target genes associated with cell adhesion and involves the regulation of angiogenesis and atherosclerosis [4].

In addition, $\beta$-catenin plays a crucial role in heart failure caused by afterload-induced cardiac hypertrophy [5]. It interacts with the transforming growth factor- $\beta$ (TGF- $\beta$ ) signaling pathway to exacerbate cardiac fibrosis and aggravate chronic heart failure [6].

Several inhibitors regulate the Wnt canonical pathway, among them Dickkopf-related protein-1 (Dkk-1) and sclerostin (Scl) [7]. Sclerostin is a 190-residue glycoprotein, which is expected to contain a cysteine-knot motif and belongs to the DAN/Cerberus family of proteins [8]. 
The secreted glycoprotein Dkk-1, a member of the Dickkopf family, is known to antagonize Wnt/ $\beta$-signaling by interaction with the LRP5/6 (low-density lipoprotein receptor-related protein 5/6). The $\mathrm{Wnt} / \beta$-catenin signaling pathway is an important mediator in cardiovascular disease and influences inflammation and vascular calcification [9].

Serum sclerostin levels significantly vary with age and are higher in male patients with stage $3 \mathrm{~b}$ and 4 CKD than in females with the same stages [10]. Previous studies showed that the expression of $\mathrm{Wnt} / \beta$-catenin signaling inhibitors such as sclerostin and Dkk-1 may attenuate further vascular calcification $[11,12]$.

We aimed to define the relationship between serum sclerostin, Dkk-1, left ventricular mass (LVM), and LVM index (LVM/BSA) in maintenance hemodialysis (HD) patients.

\section{Subjects and Methods}

2.1. Study Design. This is a cross-sectional study involving patients on regular HD in MNDU during the period Jan 2016-Jan 2017. 65 patients were recruited. The patients were grouped according to the presence or absence of left ventricular hypertrophy (LVH) calculated by LVM/BSA (LVMI) into two groups, group 1 with $\mathrm{LVMI}<125 \mathrm{gm} / \mathrm{m}^{2}$ and group 2 with LVMI $>125 \mathrm{gm} / \mathrm{m}^{2}$, and the cut point that indicated LV hypertrophy was $125 \mathrm{gm} / \mathrm{m}^{2}$ [13]. All patients were undergoing $\mathrm{HD}$ three times/week, $4 \mathrm{~h} /$ session using bicarbonate-based dialysate with calcium concentrations of $1.5 \mathrm{mmol} / \mathrm{L}$. Exclusion criteria were age $<18$ or $>75$ years, HD duration less than 6 months, patients who had a rheumatic valvular disease or underwent prosthetic valve replacement, and cardiomyopathic patients with $\mathrm{EF}<40 \%$. All patients were subjected to history taking with stress on age, smoking state, HD duration, cause of ESRD, drug history and current treatment, associated comorbidities, diabetes mellitus, hypertension, chronic liver disease, CVD, surgical history especially previous renal transplantation, and parathyroidectomy. Estimated glomerular filtration rates (eGFRs) were calculated using the Modification of Diet in Renal Disease (MDRD) equation [14]. Physical examination including weight, height, waist, midarm circumference, blood pressure, edema of lower limb, chest, heart, and abdomin, and AV fistula examination was done.

2.2. Laboratory. Fasting blood samples were obtained prior to midweek dialysis sessions for measurement of biochemical data and serum sclerostin and serum Dackkopf-1 (Dkk-1) levels. We measured serum sclerostin using the kit that uses a double-antibody sandwich enzyme-linked immunosorbent assay (ELISA) (SunRed ELISA Kit) (PELOBIOTECH GmbH-Am Klopferspitz 19-82152 Planegg, Germany, catalog number 201-12-5418 (96 tests). The sensitivity was $0.175 \mathrm{ng} / \mathrm{ml}$, with a range of assay being $0.2 \mathrm{ng} / \mathrm{ml}-60 \mathrm{ng} / \mathrm{ml}$. The serum Dkk-1 was measured using double-antibody sandwich enzyme-linked immunosorbent assay kits (SunRed ELISA Kit supplied by PELOBIOTECH $\mathrm{GmbH}$, Planegg, Germany, catalog number 201-12-0631).
The sensitivity of kits was $0.412 \mathrm{ng} / \mathrm{mL}$, with a range of assay being $0.5-150 \mathrm{ng} / \mathrm{ml}$.

Biochemical data including complete blood count, serum albumin, corrected serum calcium, phosphorus, iPTH, serum iron, TIBC, serum ferritin, total cholesterol, total triglycerides, high-density lipoprotein (HDL), and serum LDL-c concentration were obtained. Predialysis urea and postdialysis urea were recorded; Kt/v was calculated using the Daugirdas formula [15].

\subsection{Radiology Assessment}

2.3.1. 2D Echocardiography. An expert echocardiographer, who was unaware of the patients' data, performed echocardiographic measurements according to the recommendations of the American Society of Echocardiography [16]. Patients were examined prior to the HD session lying in a left lateral position in a semidark room; a two-dimensional assessment of the aortic valve and mitral valve was done using Medison SonoAce X6 device. Scoring of mitral calcification was done according to the Wilkins calcification [17] and grading of the aortic valve was done according to a previous study by Tenenbaum et al. [18].

LVM was determined by Devereux's formula (LV mass $(\mathrm{ASE})=0.8(1.04 \quad([\mathrm{LVIDD}+\mathrm{PWTD}+\mathrm{IVSTD}] 3-$ [LVIDD] $3))+0.6 \mathrm{~g}$. (LVIDD = left ventricular internal diameter in diastole, PWTD = posterior wall thickness in diastole, and IVSTD = interventricular septum thickness in diastole)) [19] and then divided by body surface area (BSA), in order to obtain LVM index [20] expressed in $\mathrm{g} / \mathrm{m}$ [2]. LVH was defined as increased LVMI [13].

\subsection{Calculation of LV Myocardial Performance Index (MPI).} MPI was calculated using (ICT + IRT)/ET formula. The mean normal value of the Tei index is $0.39 \pm 0.05$ for the LV [20]. Mitral inflow was recorded by conventional pulsed Doppler and tissue Doppler to reveal the left ventricular diastolic function by measuring $\mathrm{E}$ (early diastolic) velocity, $\mathrm{A}$ (late diastolic) flow velocity, also $\mathrm{E}_{1}$ (early diastolic) annular velocity, and $\mathrm{A}_{1}$ (late diastolic) annular velocity and calculate $\mathrm{E} / \mathrm{A}$ ratio and $\mathrm{E}_{1} / \mathrm{A}_{1}$ ratio, respectively.

2.5. Statistical Analysis. The normality of data was first tested with the Shapiro-Wilk test. Qualitative data were presented by frequency tables (frequency and percentages). Quantitative variables were presented by central indices (mean \pm standard deviation) for normally distributed variables and median (minimum-maximum) for nonnormally distributed variables. Pearson's correlation was used to correlate continuous normally distributed data while Spearman's correlation was used to correlate ordinal and nonnormally distributed data. We compared nonnormally distributed and ordinal variables between qualitative groups using the Mann-Whitney U test and Kruskal-Wallis H test. All statistical analyses were performed using SPSS version 24 (IBM Corp., Armonk, NY, USA). A $P$ value $\leq 0.05$ was considered statistically significant. 


\section{Results}

Table 1 shows the demographic, clinical, and laboratory characteristics of the whole study (mean age (years) (46.14 \pm 16.201 ), gender (male $55.6 \%$ and female $44.4 \%$ ), dry weight $(\mathrm{kg})(73.16 \pm 15.89)$, midarm circumference $(\mathrm{cm})$ (29.52 \pm 4.25$)$, waist circumference $(\mathrm{cm})(98.21 \pm 16.43)$, BMI $(26.53 \pm 5.31)$, BSA $(1.82 \pm 0.23))$. Regarding smoking, current smokers were $6(18.8 \%)$, ex-smokers were $6(18.8 \%)$, and nonsmokers were $20(62.4 \%)$. The HD duration was 35 months (6.00-168). Hypertensive patients were $85.2 \%$, diabetic patients were $13.1 \%$, and coronary artery disease was present in $9.8 \%$. Kt $/ \mathrm{v}$ was $1.13 \pm 0.28$, serum albumin $(\mathrm{g} / \mathrm{dl})$ was $3.72 \pm 0.44$, serum calcium $(\mathrm{mg} / \mathrm{dl})$ was $8.3 \pm 0.92$, serum phosphorus $(\mathrm{mg} / \mathrm{dl})$ was $4.93 \pm 1.58$, iPTH $(\mathrm{pg} / \mathrm{ml})$ was 49 (16-221), alkaline phosphatase was 145 (11-2152), and HB $(\mathrm{gm} / \mathrm{dl})$ was $9.38 \pm 1.65$.

Table 2 shows a comparative analysis of some demographic and echocardiographic data among the studied two subgroups, which shows a significant increase in mean age in the second group (with LVM/BSA $>125 \mathrm{gm} / \mathrm{m}^{2}$ ) compared with the first subgroup (with $\mathrm{LNM} / \mathrm{BSA}<125 \mathrm{gm} / \mathrm{m}^{2}$ ) $(37.61 \pm 14.47$ versus $51.74 \pm 14.93 ; P$ value $=0.001)$, a significant increase in systolic blood pressure and diastolic blood pressure in the second subgroup compared with the first subgroup $(P<0.05)$, and a highly significant increase in aortic valve calcification (AVC) and mitral valve calcification (MVC) in the second subgroup compared with the first subgroup $(P$ value $<0.001 ;<0.01)$. There are no significant changes in BMI, BSA, HD duration, DM, HTN, midarm circumference, waist circumference, dry weight, $\mathrm{E} / \mathrm{A}$, mitral E wave deceleration, E1/A1, IVRT, IVCT, ET, and MPI between the studied subgroups.

Table 3 shows a comparative analysis of some laboratory data among the studied two subgroups, which shows a highly significant decrease in the serum hemoglobin concentration $(\mathrm{gm} / \mathrm{dl})$ in the second subgroup compared with the first subgroup $(10.096 \pm 1.43$ versus $8.92 \pm 1.633$; $P$ value $=0.006)$ and significant a decrease in the serum sclerostin $(\mathrm{ng} / \mathrm{ml})$ and Dkk-1 $(\mathrm{pg} / \mathrm{ml})$ in the second subgroup compared with the first subgroup $(35.25(3.40-59.3)$ versus 7.70 (2.10-60.4) and 63 (12.00-132) versus 33 (13.00-112); $P$ value $<0.05$ for both), respectively. There are no significant differences in iron, TSAT\%, TIBC, albumin, alkaline phosphatase, cholesterol, TGs, HDL, LDL, Kt/V, Ca, PO4, and $\mathrm{PTTH}$ between the studied subgroups.

Table 4 shows the correlation between LVM and LVM/ BAS and some demographic and laboratory parameters among the studied subgroups, which shows a significant negative correlation between s. sclerostin, serum Dkk-1, and serum HDL with LVM (Rho $=-0.329,-0.427$ and $-0.268 ; P$ value $=0.010,0.001$, and -0.036 , resp.), a significant positive correlation of age, BSA, hypertension, aortic valve calcification, mitral valve calcification, and dry weight with LVM (with $P$ value $=0.001,0.027,0.019,0.036,0.001,0.02$, and 0.028 , resp.), and a nonsignificant correlation of the other parameters with LVM $(P>0.05)$. Also, there is a significant negative correlation between s. sclerostin, serum Dkk-1, BSA, hemoglobin concentration, serum albumin, midarm
TABLE 1: Some demographic, clinical, and laboratory characteristics of the whole cohort.

\begin{tabular}{lcc}
\hline Parameter & Study group $(n=65)$ \\
\hline Age (years) & $46.14 \pm 16.201$ \\
Gender & Male & $55.6 \%$ \\
& Female & $44.4 \%$ \\
Dry weight $(\mathrm{kg})$ & $73.16 \pm 15.89$ \\
Midarm circumference (cm) & $29.52 \pm 4.25$ \\
Waist circumference (cm) & $98.21 \pm 16.43$ \\
BMI & $26.53 \pm 5.31$ \\
BSA & $1.82 \pm 0.23$ \\
& Current smoker & $6(10 \%)$ \\
Smoking & Ex-smoker & $6(10 \%)$ \\
& Nonsmoker & $51(80 \%)$ \\
HD duration (months) & $35(6.00-168)$ \\
Hypertension & $85.2 \%$ \\
Diabetes & $13.1 \%$ \\
Coronary artery disease & $9.8 \%$ \\
Kt/v & $1.13 \pm 0.28$ \\
Serum albumin (g/dl) & $3.7262 \pm 0.43928$ \\
Serum calcium (mg/dl) & $8.3000 \pm 0.92718$ \\
Serum phosphorus (mg/dl) & $4.9344 \pm 1.58481$ \\
iPTH (pg/ml) & $49(16-221)$ \\
Alkaline phosphatase & $145(11-2152)$ \\
HB (gm/dl) & $9.3820 \pm 1.65081$ \\
\hline
\end{tabular}

kg: kilogram; cm: centimeter; BMI: body mass index; BSA: body surface are; $\mathrm{Kt} / \mathrm{v}$ : kinetic time over volume; gm/dl: gram/deciliter; mg/dl: milligram/ deciliter; iPTH: intact parathyroid hormone; $\mathrm{pg} / \mathrm{ml}$ : picogram/millimeter; HG: hemoglobin.

circumference, and dry weight with LVMI with LVM (Rho $=-0.257,-0.324,-0.305,-0.299,-0.294,-0.423$, and -0.286 , resp.; $P$ value $<0.05$ and 0.01 ), a significant positive correlation of age, aortic valve calcification, and mitral valve calcification with LVM (with $P$ value $=0.007,<0.001$, and 0.004 ), respectively, and a nonsignificant correlation of the other parameters with LVM $(P>0.05)$.

Table 5 shows a linear regression analysis of age, HTN, HDL, AVC, MVC, s. sclerostin, and Dkk-1 as independent predictors for LVM, which shows that hypertension is a positive predictor for LVM (with $P$ value $<0.01$ and confidence interval $(\mathrm{CI})=10.70$ to 70.50 ) and shows also that HDL and s. Dkk-1 are independent negative predictors for LVM (with $P$ value $<0.05$ and $<0.01$ ) and $\mathrm{CI}=-2.33$ to -0.117 and -0.963 to -0.204 , resp.).

Table 6 shows a linear regression analysis of age, HTN, HDL, AVC, MVC, s. sclerostin, and Dkk-1 as independent predictors for LVMI, which shows that hypertension is a positive predictor for LVMI (with $P$ value $=0.050$ and $\mathrm{CI}=-0.025$ to 36.80 ), while serum Dkk-1 was an independent negative predictor for LVMI (with $P$ value $<0.05$ and $\mathrm{CI}=-0.478$ to -0.010 ).

Table 7 shows that iPTH showed a nonstatistically significant weak positive correlation with both sclerostin and Dkk-1 $(P>0.05)$. It showed a significant positive correlation to phosphorus $(r=0.41, P=0.001)$. Both AVC and MVC showed a significant positive correlation with age $(r=0.55$, $P<0.0001$ and $r=0.38, P=0.003$, resp.). MVC was significantly negatively correlated to total cholesterol and LDL $(r=-0.27, P=0.04$ and $r=-0.28, p=0.03$, resp.). Both AVC 
TABle 2: Comparative analysis of some demographic and echocardiographic data among the studied two subgroups.

\begin{tabular}{|c|c|c|c|}
\hline Parameter & Subgroup 1 & Subgroup 2 & $P$ value \\
\hline Age (years) & $37.61 \pm 14.47$ & $51.74 \pm 14.93$ & $0.001^{* *}$ \\
\hline BMI & $27.018=$ & $26.23 \pm$ & 0.573 \\
\hline BSA & $1.835 \pm .239$ & $1.816 \pm .220$ & 0.754 \\
\hline HD duration & $\begin{array}{l}31.00 \\
(600-168)\end{array}$ & $\begin{array}{l}35.50 \\
(600-144)\end{array}$ & 0.318 \\
\hline $\mathrm{DM}$ & $8.3 \%$ & $16.2 \%$ & 0.462 \\
\hline HTN & $75.0 \%$ & 87. & 0.136 \\
\hline Midarm $\operatorname{circ}(\mathrm{cm})$ & $30.50 \pm$ & 28.89 & 0.150 \\
\hline $\mathrm{cm})$ & $97.71 \pm$ & $98.54=$ & 0.849 \\
\hline Dry weight (kg) & $74.04 \pm$ & $72.58 \pm$ & 0.729 \\
\hline $\begin{array}{l}\text { Systolic BP } \\
\text { (mmhg) }\end{array}$ & $134.58 \pm 16.41$ & 144.05 & $0.019^{*}$ \\
\hline $\begin{array}{l}\text { Diastolic BP } \\
\text { (mmhg) }\end{array}$ & 82.92 & 87.84 & $0.025^{*}$ \\
\hline $\mathrm{E} / \mathrm{A}$ & $0.905(.52-1.62)$ & $0.760(.35-1.65)$ & 0.069 \\
\hline $\begin{array}{l}\text { E_declaration (m } \\
\mathrm{sec})\end{array}$ & 154 & 5 & .316 \\
\hline $\mathrm{E} 1 / \mathrm{A} 1$ & $\begin{array}{c}0.7900 \\
(.36-1.88)\end{array}$ & $0.640(.40-1.83)$ & 0.237 \\
\hline & $76.75 \pm 11.97$ & 76. & 0.980 \\
\hline IVCT (m sec) & $71.13 \pm 9.72$ & 72.36 & 0.611 \\
\hline ET (m sec) & $285.17 \pm 20.74$ & $285.10 \pm 17.37$ & 0.990 \\
\hline MPI & $0.517 \pm .0463$ & $0.523 \pm .045$ & 0.576 \\
\hline $\mathrm{AVC}$ & $(0-2)$ & $(0-4)$ & $\begin{array}{c}< \\
0.001^{* *}\end{array}$ \\
\hline MVC & $(0-2)$ & $(0-4)$ & $0.005^{*}$ \\
\hline
\end{tabular}

* Significant at $P \leq 0.05 .{ }^{* *}$ Highly significant at $P \leq 0.001$. BMI: body mass index; BSA: body surface area; HD: hemodialysis; DM: diabetes mellitus; HTN: hypertension; circ: circumference; cm: centimeter; kg: kilogram; E/A: early diastolic mitral inflow velocity/late diastolic mitral inflow velocity; E1/ A1: early diastolic mitral annular velocity/late diastolic mitral annular velocity; IVCT: isovolumetric contraction time; $\mathrm{m}$ sec: millisecond; IVRT: isovolumetric relaxation time; MPI: myocardial performance index; AVC: aortic valve calcification; MVC: mitral valve calcification.

and MVC showed a significant negative correlation with sclerostin $(r=-0.47, P \leq 0.0001$ and $r=-0.27, P=0.04$, resp.) but they were not significantly correlated to Dkk-1, hemoglobin, iron, TSAT, TIBC, ferritin, albumin, calcium, $\mathrm{BP}$, and dialysis duration $(P>0.05)$.

Table 8 shows that both Dkk-1 and sclerostin did not show a significant correlation with different types of hyperparathyroidism treatment, $\mathrm{Kt} / \mathrm{v}$, calcium, phosphorus, ALP, TSAT, TIBC, iron, and ferritin. Dkk-1 showed a significant negative correlation with erythropoietin (EPO) treatment $(r=-0.372, P=0.003)$ while sclerostin showed a nonsignificant negative correlation to EPO treatment.

Figure 1 shows a linear negative correlation between left ventricular mass and serum sclerostin level. Figure 2 shows a linear negative correlation between left ventricular mass and serum Dickkopf-related protein-1. Figure 3 shows a linear negative correlation between left ventricular mass index and serum sclerostin level. Figure 4 shows a linear negative correlation between left ventricular mass index and serum Dickkopf-related protein-1. In Figure 5, ROC analysis between LVMI and Dkk-1 showed an AUC $=0.71$ and $P=0.005$. The cutoff value for Dkk-1 was 38.5 , at which sensitivity was $70 \%$ and specificity was $70 \%$.

\section{Discussion}

The accumulated data allow us to consider the disturbances in the FGF-23-Klotho-sclerostin ratio as one of the early markers of CKD advancement, disorders of mineral metabolism developing, and cardiovascular prognosis [21]. Alteration in the ratio of FGF-23, serum Klotho, and serum sclerostin can be regarded as an independent early marker of cardiovascular morbidity and overall prognosis of patients with CKD [22].

$55.6 \%$ of our patients were men with a mean age of $46.1 \pm 16.2$ years. The majority of them were hypertensive, while diabetes and $\mathrm{CAD}$ were present in $13 \%$ and $10 \%$ of them, respectively. $\mathrm{HB}$ concentration was $9.38 \pm 1.65 \mathrm{mg} / \mathrm{dl}$. Serum albumin, calcium, and phosphorus were within normal ranges in most patients.

With regard to the comparative analysis of the studied groups, we found a significant increase in age, AVC, and MVC in the second subgroup (with LVM/BSA > $125 \mathrm{gm}$ ). A significant increase in systolic and diastolic blood pressures was noted in subgroup 2 despite the nonsignificant difference in the percentage of hypertensive patients in the studied groups which may be attributed to better control of blood pressure and adherence to treatment in group 1 and it also indicates that the second group was subjected to a greater afterload burden. There was a nonsignificant decrease in (E/ A ratio) by conventional Doppler study in the subgroup 2 versus subgroup $1(P=0.069$; Table 2$)$ denoting more diastolic dysfunction and more increase in the preload in subgroup 2 patients. When tissue Doppler was used, the E1/ A1 ratio decreased in group 1 denoting that the tissue Doppler study revealed more patients with diastolic dysfunction in subgroup 1 patients, yet statistically nonsignificant. None of the studied patients in our study had AF. There was a significant increase in hemoglobin concentration in subgroup 1 versus subgroup 2, denoting more malnutrition in subgroup 2.

Also, serum sclerostin and Dickkopf-1 (Dkk-1) levels were significantly lower in subgroup 2 (with LVMI $>125 \mathrm{gm} / \mathrm{m}^{2}$ ) than subgroup 1 (with LVMI $<125 \mathrm{gm} /$ $\mathrm{m}^{2}$ ) which may denote a myocardial protective role for these proteins. On the contrary, Yongqiang Ji et al. reported that high levels of sclerostin in CKD patients (stage 3-5ND) were associated with more valvular calcification [23].

One possible explanation is the start of hemodialysis as it has been reported that, in patients on hemodialysis, the high sclerostin level was negatively correlated with the risk of cardiovascular death and Ji et al. did not include such patients. Chen et al. followed up 84 hemodialysis patients for (12-60 months) and concluded that patients with low baseline serum sclerostin undergoing MHD showed better survival and less CIMT [24]. Zou et al. found no correlation between sclerostin and CVEs in MHD patients [25]. These contradictory results may be attributed to different ethnic groups, different follow-up period, different assessment and measurement of sclerostin, and different primary endpoints. It is known that PTH suppresses the expression of sclerostin and/or Dkk-1 decreasing their levels [26] in contradiction to our results where it displayed a nonsignificant positive 
TABLE 3: Comparative analysis of some laboratory data among the studied two subgroups.

\begin{tabular}{lccc}
\hline Parameter & Subgroup 1 & Subgroup 2 & $P$ value \\
\hline HB $(\mathrm{gm} / \mathrm{dl})$ & $10.096 \pm 1.43$ & $8.92 \pm 1.633$ & $0.006^{*}$ \\
Iron $(\mu \mathrm{g} / \mathrm{dl})$ & $82.5(36.00-202)$ & $72(35.00-222)$ & 0.087 \\
TSAT\% & $38(13.00-85.00)$ & $32(17.00-91.00)$ & 0.111 \\
TIBC & $225.83 \pm 36.58$ & $221.08 \pm 45.195$ & 0.668 \\
S. albumin (gm/dl) & $3.85 \pm .295$ & $3.64 \pm .498$ & 0.066 \\
Alk_phosph (IU/ & $131(11.00-2152)$ & $168(64.00-1003)$ & 0.209 \\
L) & $162(93.0-243)$ & $130(79.0-375)$ & 0.140 \\
S. chol. $(\mathrm{mg} / \mathrm{dl})$ & $135.5(48.0-232)$ & $112(45.0-276)$ & 0.438 \\
S. TG $(\mathrm{mg} / \mathrm{dl})$ & $25(16.0-63.0)$ & $23(11.0-56.0)$ & 0.169 \\
S. HDL $(\mathrm{mg} / \mathrm{dl})$ & $104(29.8-159.8)$ & $87.4(39.8-332.2)$ & 0.232 \\
S. LDL $(\mathrm{mg} / \mathrm{dl})$ & $1.12 \pm .34$ & $1.13 \pm .23$ & 0.877 \\
Kt/V & $8.47 \pm .976$ & $8.19 \pm .89$ & 0.250 \\
S. Ca $(\mathrm{mg} / \mathrm{dl})$ & $4.92 \pm 1.45$ & $4.95 \pm 1.69$ & 0.945 \\
S. PO $(\mathrm{mg} / \mathrm{dl})$ & $648(10.60-1900)$ & $576(27.00-2000)$ & 0.790 \\
iPTH $(\mathrm{pg} / \mathrm{ml})$ & 35.25 & $7.70(2.10-60.4)$ & $0.013^{*}$ \\
Sclerostin $(\mathrm{ng} / \mathrm{ml})$ & $(3.40-59.3)$ & $33(13.00-112)$ & $0.011^{*}$ \\
Dkk-1 $(\mathrm{pg} / \mathrm{ml})$ & $63(12.00-132)$ & 33
\end{tabular}

*Significant at $P \leq 0.05 .{ }^{* *}$ Highly significant at $P \leq 0.001$. HB: hemoglobin; $\mathrm{gm} / \mathrm{dl}$ : gram/deciliter; $\mu \mathrm{g} / \mathrm{dl}$ : microgram/deciliter; TSAT: transferrin saturation, Alk_phosph: alkaline phosphatase; IU/L: international unit/liter; S. chol.: serum cholesterol; S. TG: serum triglycerides; S. HDL: serum highdensity lipoprotein; S. LDL: serum low-density lipoprotein; Kt/V: kinetic

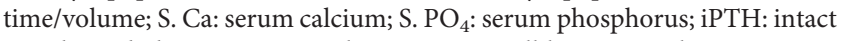
parathyroid hormone; $\mathrm{pg} / \mathrm{ml}$ : picogram/milliliter; $\mathrm{ng} / \mathrm{ml}$ : nanogram/ milliliter.

correlation with both. This could be due to increased extraosseous production of sclerostin and Dkk-1 and hyperphosphatemia, increased calcitonin exposure, and absent renal clearance of both molecules [27, 28].

Both molecules did not correlate significantly to different treatments of HPT in our study (calcium supplement, active vitamin $\mathrm{D}$ and analogs, cinacalcet, sevelamer $\mathrm{HCl}$, and parathyroidectomy) in contradiction to Kuczera et al., 2016, who reported an increase in sclerostin level (in 42 patients out of 58 included in their study) after cinacalcet therapy and related that to the decrease in PTH levels, but actually, the other 16 patients whose PTH levels did not decrease showed an increase in their sclerostin level over their study period [29] which means that further larger RCT are needed to clarify this dilemma.

In our study, sclerostin and Dkk-1 did not correlate significantly to Kt/v, calcium, phosphorus, ALP, iron, TSAT, TIBC, and ferritin. Both molecules correlated negatively to EPO treatment but only Dkk-1 showed significance $(r=-0.372, P=0.003)$. This finding is overlooked and rarely found in the literature. Sharba and Al Zahid, 2016, found a positive correlation between EPO and sclerostin in their study on 21 male patients (12 on dialysis and 9 not on dialysis; duration of dialysis $20.9 \pm 3.25$ months) [30]. More detailed studies are needed to explore this interesting issue.

A study done by Stróżecki and colleagues concluded that patients with vascular calcification (VC) were older and had higher LVMI and no significant differences were found with respect to $\mathrm{PTH}$, phosphorus calcium which is in accordance with our results. VC coexists with hypertrophy of the left ventricle especially when both valves are calcified. Even shortlived incidents involving increased product $\mathrm{Ca} \times \mathrm{P}$ can lead to cardiovascular calcification [31, 32].

LVH has a prevalence of approximately $40 \%$ in patients with chronic kidney disease (CKD), and it progressively increases with CKD progression up to 75\% in ESRD patients $[33,34]$. Foley et al. followed 596 patients on hemodialysis with no previous history of heart disease to determine whether the frequency of LVH correlates with the length of the dialysis. After 18 months of dialysis, the author recorded that $62 \%$ of patients had an increased LV mass index and $49 \%$ had developed LV failure [35]. CKD patients are faced with both pressure and volume overload states; however, sustained overload in combination with CKD-associated factors such as SHPT, RAAS activation, and anemia may result in maladaptive LVH until the final picture of uremic cardiomyopathy ensues [36-39].

Our results reveal that there was a significant negative correlation of sclerostin and Dkk-1 with left ventricular mass (LVM). LVM had a significant negative correlation with HDL, while it showed a significant positive correlation with age and a significant positive correlation with BSA, hypertension, AVC, MVC, and dry weight.

With linear regression analysis for LVM as a dependent factor, there was a nonsignificant prediction of age, serum sclerostin, aortic valve calcification, and mitral valve calcification for LVM; on the other hand, hypertension had a significant positive independent prediction for LVM, while serum HDL and serum DDK-1 were negative significant independent indicators for LVM.

As regards correlations with LVM/BSA (LVMI), there was a significant negative correlation of serum sclerostin and Dkk-1 with LVMI and a significant negative correlation with hemoglobin, albumin, midarm circumference, and dry weight with LVMI, while there was a highly significant positive correlation with age, AVC, and MVC with LVMI. With linear regression analysis for LVMI, there was a nonsignificant prediction of age, HDL, MVC, and serum sclerostin for LVMI; on the other hand, serum DDK-1 was a significant negative indicator for LVMI and hypertension was a weak significant positive predictor for LVMI ( $P$ value $=0.05$ ).

Our results are in disagreement with Brovko and colleagues, 2018, who had done a study on 131 CKD Russian patients (stages $1-5$, average age $42.4 \pm 13.7$ years) and revealed that, with univariate analysis, serum sclerostin levels correlated positively with LVM index $(r=0.545$; $P<0.01)$ but with multivariate regression, it was negatively correlated to CVC and suggested that it may protect the heart and vessels against calcification with CKD advancement [40].

It is well known that Wnt- $\beta$-catenin signaling pathway inhibition by sclerostin and Dkk-1 protects against cardiac AV and MV calcifications and both have a significant negative correlation with both valves' calcification [41, 42]. Our study revealed that AVC and MVC had a significant negative correlation with sclerostin but a nonsignificant negative correlation with Dkk-1 which coincides with Yang et al., 2015, who reported that circulating sclerostin but not Dkk-1 is inversely 
TABLE 4: Correlation between LVM and LVM/BSA and some demographic and laboratory parameters among the studied subgroups.

\begin{tabular}{|c|c|c|c|c|}
\hline & \multicolumn{2}{|c|}{ LVM } & \multicolumn{2}{|c|}{ LVMI } \\
\hline & $r$ & $P$ & $r$ & $P$ \\
\hline S. sclerostin (ng/ml) & -0.329 & $0.010^{*}$ & -0.257 & $0.046^{*}$ \\
\hline S. Dkk-1 (pg/dl) & -0.427 & $0.001^{* *}$ & -0.324 & $0.012^{*}$ \\
\hline Age (years) & 0.409 & $0.001^{* *}$ & 0.352 & $0.007^{*}$ \\
\hline BMI & 0.219 & 0.085 & -0.199 & 0.118 \\
\hline BSA & 0.278 & $0.027^{*}$ & -0.305 & $0.015^{*}$ \\
\hline HD_duration & -0.153 & 0.264 & 0.015 & 0.979 \\
\hline Gender & -0.112 & 0.380 & 0.153 & 0.232 \\
\hline HTN & 0.300 & $0.019^{*}$ & 0.247 & 0.054 \\
\hline $\mathrm{HB}(\mathrm{gm} / \mathrm{dl})$ & -0.245 & 0.057 & -0.299 & $0.019^{*}$ \\
\hline S. albumin $(\mathrm{gm} / \mathrm{dl})$ & -0.229 & 0.076 & -0.294 & $0.021^{*}$ \\
\hline Syst_BP (mmhg) & 0.243 & 0.059 & 0.249 & 0.053 \\
\hline Diast BP (mmhg) & 0.251 & 0.051 & 0.211 & 0.103 \\
\hline S. cholesterol & -0.126 & 0.334 & -0.205 & 0.112 \\
\hline S. TG (mg/dl) & -0.024 & 0.855 & -0.179 & 0.166 \\
\hline S. HDL (mg/dl) & -0.268 & $0.036^{*}$ & -0.161 & 0.214 \\
\hline S. LDL (mg/dl) & -0.076 & 0.563 & -0.158 & 0.225 \\
\hline AVC & 0.417 & $0.001^{* *}$ & 0.464 & $<0.001^{* *}$ \\
\hline MVC & 0.297 & $0.02^{*}$ & 0.360 & $0.004^{*}$ \\
\hline Mid_arm_circ (cm) & 0.067 & 0.609 & -0.423 & $0.001^{* *}$ \\
\hline Waist_circ $(\mathrm{cm})$ & 0.204 & 0.115 & -0.128 & 0.326 \\
\hline Dry_weight (kg) & 0.282 & $0.028^{*}$ & -0.286 & $0.026^{*}$ \\
\hline $\mathrm{Kt} / \mathrm{V}$ & -0.046 & 0.723 & 0.183 & 0.158 \\
\hline S. Ca (mg/dl) & -0.085 & 0.514 & -0.074 & 0.573 \\
\hline S. $\mathrm{PO}_{4}(\mathrm{mg} / \mathrm{dl})$ & 0.242 & 0.060 & -0.028 & 0.831 \\
\hline iPTH (pg/dl) & 0.023 & 0.787 & -0.035 & 0.861 \\
\hline
\end{tabular}

Spearman's correlation used. *Significant at $P \leq 0.05 ;{ }^{* *}$ highly significant at $P \leq 0.001$. LVM: left ventricular mass; LVM/BSA: left ventricular mass/body surface area; S. Dkk-1: serum Dickkopf-1; BMI: body mass index; BSA: body surface area; HD: hemodialysis; HTN: hypertension; HB (gm/dl): hemoglobin concentration (gram/deciliter); Syst_BP: systolic blood pressure; Diast BP: diastolic blood pressure; mmhg: millimeter Mercury; S. TG; serum triglyceride; S. HDL: serum high-density lipoprotein; S. LDL: serum low-density lipoprotein; AVC: aortic valve calcification; MVC: mitral valve calcification; circ: circumference; Kt/V: kinetic time/volume; S. Ca: serum calcium; S. $\mathrm{PO}_{4}$ : serum phosphorus; iPTH: intact parathyroid hormone; mg/dl: milligram/deciliter; $\mathrm{pg} / \mathrm{dl}:$ picogram/deciliter; $\mathrm{ng} / \mathrm{dl}:$ nanogram/deciliter.

associated with aortic calcifications and future cardiovascular events [43]. Krishna et al. reported that sclerostin decreases the expression of genes involved in matrix degradation and calcification and thereby inhibits atherosclerosis; it is likely that sclerostin could function as an inhibitor of vascular calcification [44].

On the contrary, other studies showed that elevated serum sclerostin levels were seen in patients with aortic valve calcification with increased upregulation of sclerostin mRNA [45]. Several elements could have contributed to these conflicting results. Studies investigated the presence of vascular calcification at different anatomical locations and used different statistical analyses (by adjusting for different potential confounding factors). In addition, differences in the time period between administration of enoxaparin (or other low molecular weight heparins that are used as anticoagulants) and blood collection could also be important, since enoxaparin stimulates the release of sclerostin into the circulation. This also implies that the heterogeneity of study populations-patients at different CKD stages, with or without dialysis treatment, whether or not they receive low molecular weight heparins-contributes to the observed inconsistency. Lastly, it is known that there are large discrepancies between sclerostin assays. The antibodies that are used in the distinct assays bind different epitopes; therefore, some antibodies will capture only the intact sclerostin molecule, while others might also bind to sclerostin fragments [46].

In our study, sclerostin and Dkk-1 had a significant negative correlation with LVM and LVM/BSA. Moreover, Dkk-1 appeared to be an independent indicator of LVM and LVM/BSA and they may be acting as protectors against LV hypertrophy or may be only associated with LV hypertrophy in CKD patients.

Van de Schans and colleagues demonstrated that interruption of Wnt signaling in the mice lacking the Dvl-1 gene delays the onset of pressure overload-induced cardiac hypertrophy. Therefore, the Wnt/Frizzled pathway may provide novel therapeutic targets for antihypertrophic therapy [47].

Because Wnt signaling is very complex and its effects may be quite varied according to the cell system, specific ligands/ receptors involved, and timing of any interventions which presents a challenge to investigators, but it offers rich possibilities for new insights into cardiac pathophysiology and the identification of new therapeutic targets [48].

Limitations of this study include the relatively small population studied in a single-center and the cross-sectional design. However, to our knowledge, there are only 
TABLE 5: Linear regression analysis of LMV with some parameters among the studied subgroups.

\begin{tabular}{|c|c|c|c|c|c|c|}
\hline \multirow[t]{2}{*}{ Parameter } & \multicolumn{2}{|c|}{$\begin{array}{l}\text { Unstandardized } \\
\text { coefficients }\end{array}$} & \multirow{2}{*}{$\begin{array}{c}\text { Standardized coefficients } \\
\text { Beta }\end{array}$} & \multirow[t]{2}{*}{$P$ value* } & \multicolumn{2}{|c|}{$95.0 \%$ confidence interval for B } \\
\hline & $\mathrm{B}$ & Std. error & & & Lower bound & Upper bound \\
\hline S (constant) & 214.80 & 27.39 & & $<0.001$ & 159.72 & 269.88 \\
\hline Age & 0.73 & 0.408 & 0.216 & 0.079 & -0.088 & 1.55 \\
\hline HTN & 40.65 & 14.89 & 0.279 & 0.009 & 10.70 & 70.50 \\
\hline HDL & -1.22 & 0.550 & -0.232 & 0.031 & -2.33 & -0.117 \\
\hline AVC & 9.62 & 6.287 & 0.227 & 0.132 & -3.015 & 22.268 \\
\hline MVC & 1.94 & 6.00 & 0.043 & 0.748 & -10.13 & 14.014 \\
\hline S. sclerostin & 0.049 & 0.325 & 0.018 & 0.882 & -0.605 & 0.703 \\
\hline Dkk-1 & -0.58 & 0.189 & -0.354 & 0.003 & -0.963 & -0.204 \\
\hline
\end{tabular}

Dependent variable: LVM. *Significant $P \leq 0.05$. LVM: left ventricular mass; HTN: hypertension; HDL: high-density lipoprotein; AVC: aortic valve calcification; MVC: mitral valve calcification; Dkk-1: Dickkopf-1.

TABLE 6: Linear regression analysis of LMV/BSA with some parameters among the studied subgroups.

\begin{tabular}{|c|c|c|c|c|c|c|}
\hline \multirow[t]{2}{*}{ Parameter } & \multicolumn{2}{|c|}{$\begin{array}{l}\text { Unstandardized } \\
\text { coefficients }\end{array}$} & \multirow{2}{*}{$\begin{array}{c}\text { Standardized coefficients } \\
\text { Beta }\end{array}$} & \multirow[t]{2}{*}{$P$ value* } & \multicolumn{2}{|c|}{$95.0 \%$ confidence interval for B } \\
\hline & B & Std. error & & & Lower bound & Upper bound \\
\hline$S$ (constant) & 114.11 & 16.88 & & $<0.001$ & 80.16 & 148.06 \\
\hline Age & 0.189 & 0.251 & 0.101 & 0.455 & -0.316 & 0.694 \\
\hline HTN & 18.43 & 9.18 & 0.229 & 0.050 & -0.025 & 36.80 \\
\hline HDL & -0.436 & 0.339 & -0.150 & 0.205 & -1.118 & 0.246 \\
\hline AVC & 7.638 & 3.876 & 0.326 & 0.055 & -0.155 & 15.430 \\
\hline MVC & 2.320 & 3.701 & 0.092 & 0.534 & -5.121 & 9.761 \\
\hline S. sclerostin & 0.079 & 0.201 & 0.053 & 0.695 & -0.324 & 0.482 \\
\hline DKK & -0.244 & 0.116 & -0.268 & $0.041^{*}$ & -0.478 & -0.010 \\
\hline
\end{tabular}

Dependent variable: LVM/BSA. *Significant at $P \leq 0.05$. LVM/BSA: left ventricular mass/body surface area; HTN: hypertension; HDL: high-density lipoprotein; AVC: aortic valve calcification; MVC: mitral valve calcification; Dkk-1: dickkopf-1.

TABle 7: Correlation between AVC, MVC, iPTH, and some clinical and chemical variables.

\begin{tabular}{|c|c|c|c|c|c|c|}
\hline & \multicolumn{2}{|c|}{$\mathrm{AVC}$} & \multicolumn{2}{|c|}{ MVC } & \multicolumn{2}{|c|}{ iPTH } \\
\hline & $r$ & $P$ & $r$ & $P$ & $r$ & $P$ \\
\hline Age & 0.55 & $<0.0001^{*}$ & 0.38 & $0.003^{*}$ & -0.05 & 0.72 \\
\hline HD duration & 0.23 & 0.1 & 0.01 & 0.95 & 0.24 & 0.08 \\
\hline Ferritin & -0.09 & 0.48 & -0.05 & 0.69 & -0.006 & 0.96 \\
\hline Hemoglobin & -0.22 & 0.09 & -0.18 & 0.16 & 0.22 & 0.09 \\
\hline Iron & -0.1 & 0.47 & -0.08 & 0.5 & 0.12 & 0.35 \\
\hline TIBC & 0.04 & 0.78 & -0.13 & 0.33 & -0.01 & 0.93 \\
\hline TSAT & -0.09 & 0.5 & -0.05 & 0.72 & 0.08 & 0.55 \\
\hline Albumin & -0.15 & 0.24 & -0.17 & 0.2 & 0.18 & 0.16 \\
\hline Syst. BP & 0.12 & 0.35 & 0.04 & 0.75 & 0.06 & 0.66 \\
\hline Diast. BP & 0.1 & 0.47 & 0.08 & 0.54 & -0.01 & 0.93 \\
\hline Cholesterol & -0.17 & 0.19 & -0.27 & $0.04^{*}$ & 0.03 & 0.82 \\
\hline $\mathrm{HDL}$ & 0.06 & 0.65 & 0.09 & 0.5 & 0.04 & 0.78 \\
\hline LDL & -0.17 & 0.19 & -0.28 & $0.03^{*}$ & 0.02 & 0.86 \\
\hline $\mathrm{Kt} / \mathrm{v}$ & -0.01 & 0.91 & -0.12 & 0.36 & 0.03 & 0.82 \\
\hline Calcium & -0.02 & 0.89 & 0.09 & 0.52 & 0.03 & 0.8 \\
\hline Phosphorus & -0.09 & 0.48 & -0.04 & 0.75 & 0.41 & $0.001^{*}$ \\
\hline Sclerostin & -0.47 & $<0.0001^{*}$ & -0.27 & $0.04^{*}$ & 0.15 & 0.24 \\
\hline Dkk-1 & -0.15 & 0.25 & -0.16 & 0.21 & 0.03 & 0.8 \\
\hline iPTH & -0.18 & 0.18 & -0.03 & 0.85 & & \\
\hline
\end{tabular}

Spearman's correlation used. *Significant when $P<0.05$. 
TABLE 8: Correlation between Dkk-1, sclerostin, and some clinical chemical variables.

\begin{tabular}{|c|c|c|c|}
\hline & & Dkk-1 & Sclerostin \\
\hline \multirow{2}{*}{ HPT_ttt } & $r$ & 0.041 & 0.024 \\
\hline & $P$ & 0.754 & 0.854 \\
\hline \multirow{2}{*}{ Kt_V } & $r$ & 0.155 & 0.158 \\
\hline & $P$ & .233 & 0.224 \\
\hline \multirow{2}{*}{ S. Ca } & $r$ & 0.023 & 0.106 \\
\hline & $P$ & 0.857 & 0.415 \\
\hline \multirow[b]{2}{*}{ S. $\mathrm{PO}_{4}$} & $r$ & -0.089 & -0.005 \\
\hline & $P$ & 0.494 & 0.971 \\
\hline \multirow{2}{*}{ Alk_phosphatase } & $r$ & 0.001 & 0.108 \\
\hline & $P$ & 0.994 & 0.408 \\
\hline \multirow{2}{*}{ TSAT } & $r$ & 0.059 & 0.197 \\
\hline & $P$ & 0.654 & 0.128 \\
\hline \multirow{2}{*}{ TIBC } & $r$ & -0.029 & -0.105 \\
\hline & $P$ & 0.825 & 0.420 \\
\hline \multirow{2}{*}{ Iron } & $r$ & 0.020 & 0.091 \\
\hline & $P$ & 0.880 & 0.484 \\
\hline \multirow{2}{*}{ S. ferritin } & $r$ & 0.109 & 0.174 \\
\hline & $P$ & 0.401 & 0.180 \\
\hline \multirow{2}{*}{ Erythropoietin } & $r$ & -0.372 & -0.134 \\
\hline & $P$ & $0.003^{*}$ & 0.303 \\
\hline
\end{tabular}

Spearman's correlation used. *Significant when $P<0.05$. HPT_ttt $=$ hyperparathyroidism treatment. TIBC $=$ total iron-binding capacity.

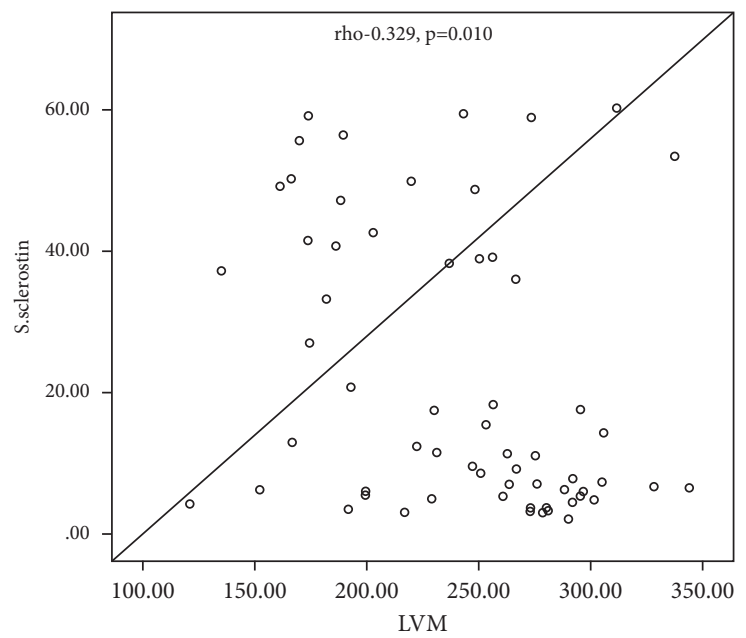

Figure 1: Linear negative correlation between the left ventricular mass and serum sclerostin level.

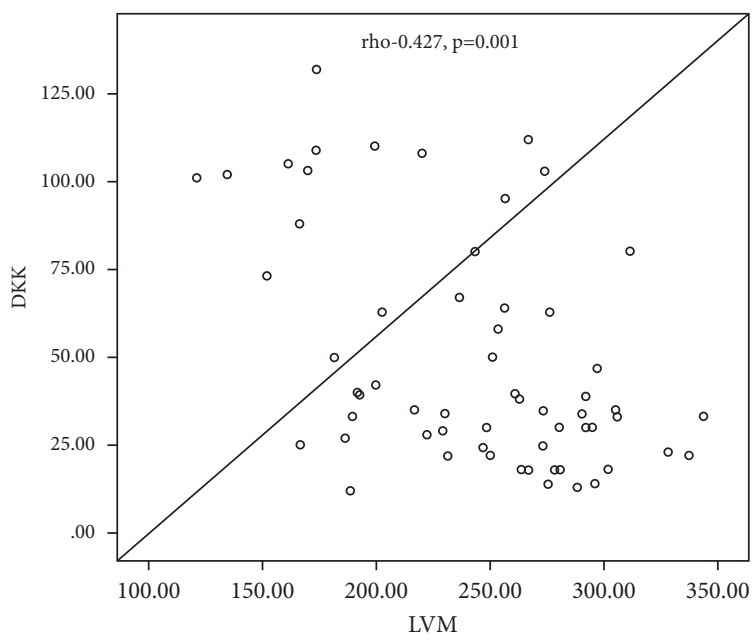

FiguRE 2: Linear negative correlation between the left ventricular mass and serum Dickkopf-related protein-1. 


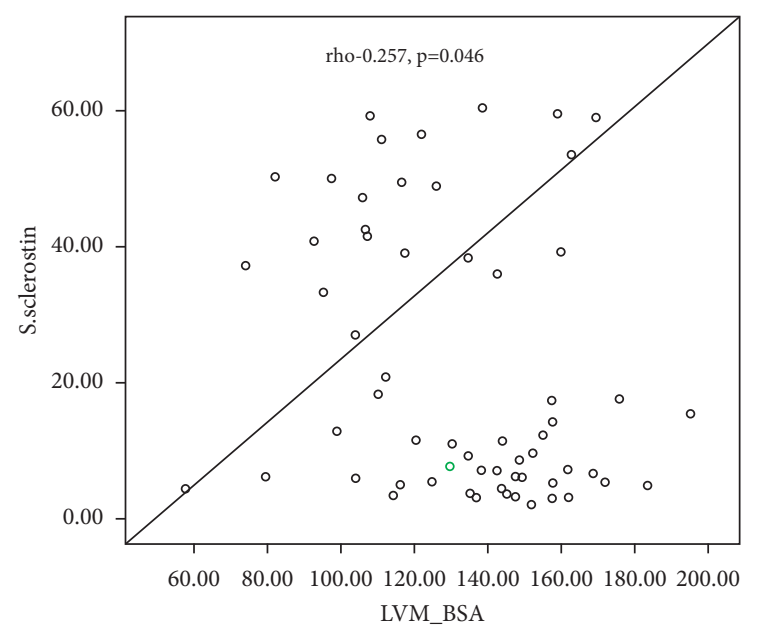

FIgURE 3: Linear negative correlation between the left ventricular mass index and serum sclerostin level.

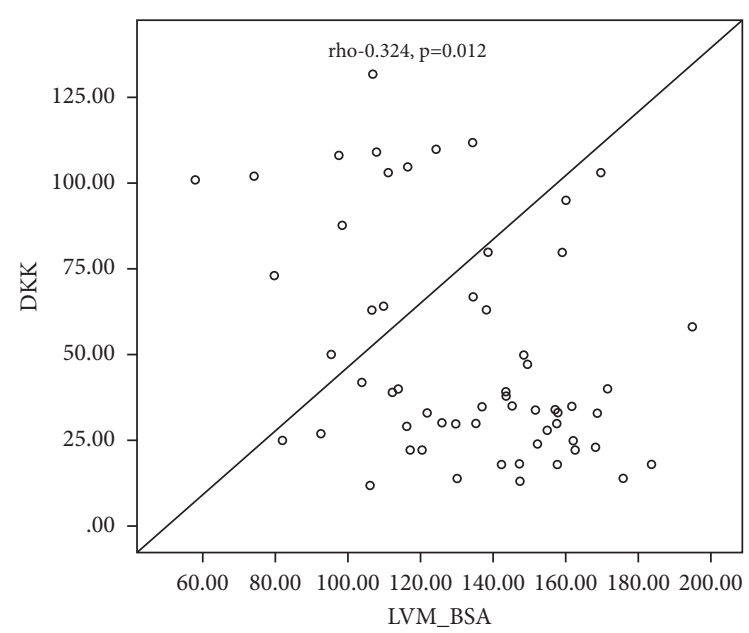

FIGURE 4: Linear negative correlation between the left ventricular mass index and serum Dickkopf-related protein-1.

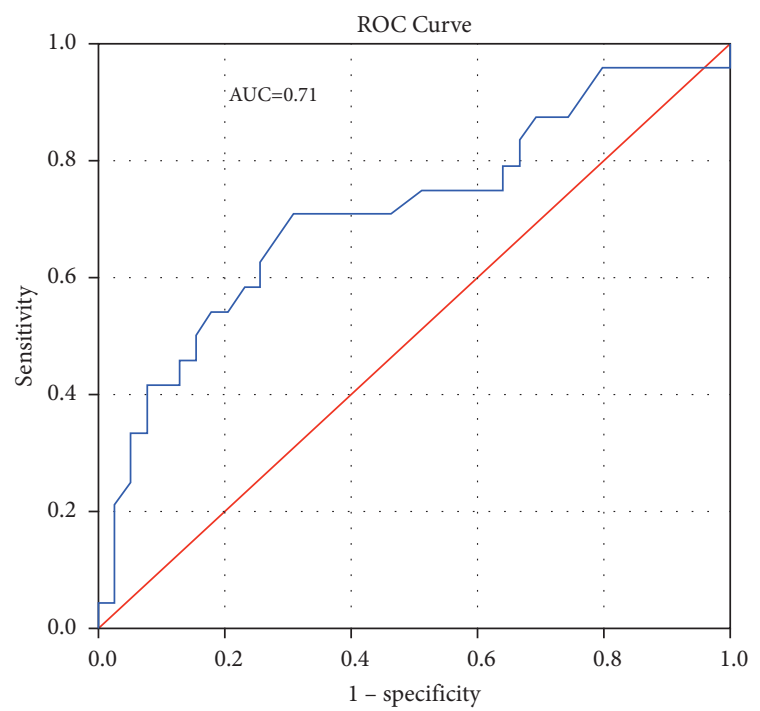

FIGURE 5: ROC analysis between LVMI and Dkk-1. limited studies addressing the relationship between Wnt pathway inhibitors and LVMI. More studies are needed to ascertain the obtained results.

\section{Data Availability}

All data analyzed during this study are included within this manuscript.

\section{Ethical Approval}

The study was approved by the Institutional Research Board (IRB) of the Faculty of Medicine, Mansoura University, in accordance with the Declaration of Helsinki.

\section{Consent}

All participants signed written informed consent before the start of the study.

\section{Conflicts of Interest}

All the authors declare no conflicts of interest in this work.

\section{Authors' Contributions}

Bahie and Rasha formulated the idea of the research. Rasha performed laboratory tests. Dalia and Mohamed created tables. Wahab and El-Said wrote the initial manuscript. Wahab and El Kannishy reviewed the final version.

\section{Acknowledgments}

The authors acknowledge the great efforts and contributions of all staff members of MNDU and all participants in this study since without them, this study would have never been accomplished.

\section{References}

[1] C. Zoccali, F. A. Benedetto, F. Mallamaci et al., "Left ventricular mass monitoring in the follow-up of dialysis patients: prognostic value of left ventricular hypertrophy progression," Kidney International, vol. 65, no. 4, pp. 1492-1498, 2004.

[2] R. B. Devereux, B. Dahlöf, D. Levy, and M. A. Pfeffer, "Comparison of enalapril versus nifedipine to decrease left ventricular hypertrophy in systemic hypertension (the PRESERVE trial)," The American Journal of Cardiology, vol. 78, no. 1, pp. 61-65, 1996.

[3] H. Haybar, E. Khodadi, and S. Shahrabi, "Wnt/ $\beta$-catenin in ischemic myocardium: interactions and signaling pathways as a therapeutic target," Heart Failure Reviews, vol. 24, no. 3, pp. 411-419, 2019.

[4] H. Williams, C. A. E. Mill, B. A. Monk, S. Hulin-Curtis, J. L. Johnson, and S. J. George, "Wnt2 and WISP-1/CCN4 induce intimal thickening via promotion of smooth muscle cell migration," Arteriosclerosis, Thrombosis, and Vascular Biology, vol. 36, no. 7, pp. 1417-1424, 2016.

[5] Y. Zhang, L. Zhang, X. Fan et al., "Captopril attenuates TACinduced heart failure via inhibiting Wnt3a/ $\beta$-catenin and Jak2/Stat3 pathways," Biomedicine \& Pharmacotherapy, vol. 113, p. 108780, 2019. 
[6] A. Taiyab, J. Holms, and J. A. West-Mays, " $\beta$-catenin $/ \mathrm{Smad} 3$ interaction regulates transforming growth factor- $\beta$-induced epithelial to mesenchymal transition in the lens," International Journal of Molecular Sciences, vol. 20, no. 9, p. 2078, 2019.

[7] Y. Schmitz, K. Rateitschak, and O. Wolkenhauer, "Analysing the impact of nucleo-cytoplasmic shuttling of $\beta$-catenin and its antagonists APC, Axin and GSK3 on Wnt $/ \beta$-catenin signalling," Cellular Signalling, vol. 25, no. 11, pp. 2210-2221, 2013.

[8] V. Veverka, A. J. Henry, P. M. Slocombe et al., "Characterization of the structural features and interactions of sclerostin," Journal of Biological Chemistry, vol. 284, no. 16, pp. 10890-10900, 2009.

[9] S. Foulquier, E. P. Daskalopoulos, G. Lluri, K. C. M. Hermans, A. Deb, and W. M. Blankesteijn, "WNT signaling in cardiac and vascular disease," Pharmacological Reviews, vol. 70, no. 1, pp. 68-141, 2018.

[10] S. Thambiah, R. Roplekar, P. Manghat et al., "Circulating sclerostin and Dickkopf-1 (DKK1) in predialysis chronic kidney disease (CKD): relationship with bone density and arterial stiffness," Calcified Tissue International, vol. 90, no. 6, pp. 473-480, 2012.

[11] K. J. Claes, L. Viaene, S. Heye, B. Meijers, P. d'Haese, and P. Evenepoel, "Sclerostin: another vascular calcification inhibitor?" Journal of Clinical Endocrinology \& Metabolism, vol. 98, no. 8, pp. 3221-3228, 2013.

[12] L. Hortells, C. Sosa, N. Guillén, S. Lucea, Á. Millán, and V. Sorribas, "Identifying early pathogenic events during vascular calcification in uremic rats," Kidney International, vol. 92, no. 6, pp. 1384-1394, 2017.

[13] M. J. Koren, R. B. Devereux, P. N. Casale, D. D. Savage, and J. H. Laragh, "Relation of left ventricular mass and geometry to morbidity and mortality in uncomplicated essential hypertension," Annals of Internal Medicine, vol. 114, no. 5, pp. 345-352, 1991.

[14] A. S. Levey, J. P. Bosch, J. B. Lewis, T. Greene, N. Rogers, and D. Roth, "A more accurate method to estimate glomerular filtration rate from serum creatinine: a new prediction equation," Annals of Internal Medicine, vol. 130, no. 6, pp. 461-470, 1999.

[15] J. T. Daugirdas, "Second generation logarithmic estimates of single-pool variable volume $\mathrm{Kt} / \mathrm{V}$ : an analysis of error," Journal of the American Society of Nephrology, vol. 4, no. 5, pp. 1205-1213, 1993.

[16] N. B. Schiller, P. M. Shah, M. Crawford et al., "Recommendations for quantitation of the left ventricle by two-dimensional echocardiography," Journal of the American Society of Echocardiography, vol. 2, no. 5, pp. 358-367, 1989.

[17] G. T. Wilkins, A. E. Weyman, V. M. Abascal, P. C. Block, and I. F. Palacios, "Percutaneous balloon dilatation of the mitral valve: an analysis of echocardiographic variables related to outcome and the mechanism of dilatation," Heart, vol. 60, no. 4, pp. 299-308, 1988.

[18] A. Tenenbaum, E. Z. Fisman, E. Schwammenthal et al., "Aortic valve calcification in hypertensive patients: prevalence, risk factors and association with transvalvular flow velocity," International Journal of Cardiology, vol. 94, no. 1, pp. 7-13, 2004.

[19] R. B. Devereux, D. R. Alonso, E. M. Lutas et al., "Echocardiographic assessment of left ventricular hypertrophy: comparison to necropsy findings," The American Journal of Cardiology, vol. 57, no. 6, pp. 450-458, 1986.
[20] C. Tei, "New non-invasive index for combined systolic and diastolic ventricular function," Journal of Cardiology, vol. 26, no. 2, pp. 135-136, 1995.

[21] L. Y. Milovanova, V. Fomin, L. V. Lysenko et al., "Disorders in the system of mineral and bone metabolism regulators-FGF23, klotho and sclerostin-in chronic kidney disease: clinical significance and possibilities for correction," in Chronic Kidney Disease-from Pathophysiology to Clinical ImprovementsIntechOpen, London, UK, 2017.

[22] G. Hampson, S. Edwards, S. Conroy, G. M. Blake, I. Fogelman, and M. L. Frost, "The relationship between inhibitors of the Wnt signalling pathway (Dickkopf-1(DKK1) and sclerostin), bone mineral density, vascular calcification and arterial stiffness in post-menopausal women," Bone, vol. 56, no. 1, pp. 42-47, 2013.

[23] Y. Q. Ji, L. N Guan, S. X Yu et al., "Serum sclerostin as a potential novel biomarker for heart valve calcification in patients with chronic kidney disease," European Review for Medical and Pharmacological Sciences, vol. 22, pp. 8822-8829, 2018.

[24] A. Chen, Y. Sun, J. Cui et al., "Associations of sclerostin with carotid artery atherosclerosis and all-cause mortality in Chinese patients undergoing maintenance hemodialysis," BMC Nephrology, vol. 19, no. 1, p. 264, 2018.

[25] Y. Zou, M. Yang, J. Wang et al., "Association of sclerostin with cardiovascular events and mortality in dialysis patients," Renal Failure, vol. 42, no. 1, pp. 282-288, 2020.

[26] I. Kramer, G. G. Loots, A. Studer, H. Keller, and M. Kneissel, "Parathyroid hormone (PTH)-induced bone gain is blunted in SOST overexpressing and deficient mice," Journal of Bone and Mineral Research, vol. 25, no. 2, pp. 178-189, 2010.

[27] F. L. C. Gonçalves, R. M. Elias, L. M. Dos Reis et al., "Serum sclerostin is an independent predictor of mortality in hemodialysis patients," BMC Nephrology, vol. 15, no. 1, p. 190, 2014.

[28] R. B. De Oliveira, F. G. Graciolli, L. M. Dos Reis et al., "Disturbances of Wnt/-catenin pathway and energy metabolism in early CKD: effect of phosphate binders," Nephrology Dialysis Transplantation, vol. 28, no. 10, pp. 2510-2517, 2013.

[29] P. Kuczera, M. Adamczak, and A. Więcek, "Treatment with cinacalcet increases plasma sclerostin concentration in hemodialysis patients with secondary hyperparathyroidism," BMC Nephrology, vol. 17, no. 1, p. 176, 2016.

[30] I. R. Sharba and J. M. Al-Zahid, "Relationship of sclerostin with PTH and erythropoietin in-patient with CKD on dialysis in AL-Najaf province," International Journal of Advanced Research, vol. 4, pp. 601-610, 2016.

[31] P. Stróżecki, G. Odrowąż-Sypniewska, and J. Manitius, "Cardiac valve calcifications and left ventricular hypertrophy in hemodialysis patients," Renal Failure, vol. 27, no. 6, pp. 733-738, 2005.

[32] K. Nitta, T. Akiba, K. Uchida et al., "Left ventricular hypertrophy is associated with arterial stiffness and vascular calcification in hemodialysis patients," Hypertension Research, vol. 27, no. 1, pp. 47-52, 2004.

[33] R. N. Foley, P. S. Parfrey, J. D. Harnett et al., "Clinical and echocardiographic disease in patients starting end-stage renal disease therapy," Kidney International, vol. 47, no. 1, pp. 186-192, 1995.

[34] R. J. Middleton, P. S. Parfrey, and R. N. Foley, "Left ventricular hypertrophy in the renal patient," Journal of the American Society of Nephrology, vol. 12, no. 5, pp. 1079-1084, 2001.

[35] R. N. Foley, B. M. Curtis, E. W. Randell, and P. S. Parfrey, "Left ventricular hypertrophy in new hemodialysis patients 
without symptomatic cardiac disease," Clinical Journal of the American Society of Nephrology, vol. 5, no. 5, pp. 805-813, 2010.

[36] M. G. Shlipak, L. F. Fried, M. Cushman et al., "Cardiovascular mortality risk in chronic kidney disease," Jama, vol. 293, no. 14, pp. 1737-1745, 2005.

[37] G. M. London, "Cardiovascular disease in chronic renal failure: pathophysiologic aspects," in Seminars in DialysisJohn Wiley \& Sons, Hoboken, NJ, USA, 2003.

[38] S. Y. Hayashi, M. Rohani, B. Lindholm et al., "Left ventricular function in patients with chronic kidney disease evaluated by colour tissue Doppler velocity imaging," Nephrology Dialysis Transplantation, vol. 21, no. 1, pp. 125-132, 2006.

[39] A. Bahie, G. El-Said, and A. M. Wahab, "Relation between carotid intimal medial thickness and left ventricular mass \& left ventricular mass indices in maintenance hemodialysis patients," Therapeutic Apharesis and Dialysis, vol. 2021, pp. 1-11, 2021.

[40] M. Brovko, L. Milovanova, V. Fomin et al., "Sp292Serum sclerostin protects against cardiovascular calcification in Ckd patients," Nephrology Dialysis Transplantation, vol. 33, no. suppl_1, p. i441, 2018.

[41] G. El-Said, M. AbdAlbary, A. Bahi, R. R. Elzehry, and G. ElKannishy, "Relation of wnt-signaling antagonist sclerostin to valvular calcification and carotid intimal-medial thickness in hemodialysis patients," Journal of The Egyptian Society of Nephrology and Transplantation, vol. 18, no. 4, p. 103, 2018.

[42] D. Y. M. El-Sayed, A. Bahie, R. R. Elzehry, G. El-Kannishy, and A. M. Wahab, "Association between serum dickkopf-1 (Dkk-1) glycoprotein and calcific deposits on cardiac valves and carotid intimal-medial thickness in hemodialysis patients," Cardiorenal Medicine, vol. 10, pp. 313-322, 2020.

[43] C.-Y. Yang, Z.-F. Chang, Y.-P. Chau et al., "Circulating Wnt/ $\beta$-catenin signalling inhibitors and uraemic vascular calcifications," Nephrology Dialysis Transplantation, vol. 30, no. 8, pp. 1356-1363, 2015.

[44] S. M. Krishna, S.-W. Seto, R. J. Jose et al., "Wnt signaling pathway inhibitor sclerostin inhibits angiotensin II-induced aortic aneurysm and atherosclerosis," Arteriosclerosis, Thrombosis, and Vascular Biology, vol. 37, no. 3, pp. 553-566, 2017.

[45] R. Koos, V Brandenburg, A. H Mahnken et al., "Sclerostin as a potential novel biomarker for aortic valve calcification: an invivo and ex-vivo study," Journal of Heart Valve Disease, vol. 22, no. 3, pp. 317-325, 2013.

[46] A. De Maré, P. C. D’Haese, and A. Verhulst, "The role of sclerostin in bone and ectopic calcification," International Journal of Molecular Sciences, vol. 21, no. 9, p. 3199, 2020.

[47] V. A. M. Van De Schans, S. W. M. van den Borne, A. E. Strzelecka et al., "Interruption of Wnt signaling attenuates the onset of pressure overload-induced cardiac hypertrophy," Hypertension, vol. 49, no. 3, pp. 473-480, 2007.

[48] K. Dawson, M. Aflaki, and S. Nattel, "Role of the Wnt-frizzled system in cardiac pathophysiology: a rapidly developing, poorly understood area with enormous potential," The Journal of Physiology, vol. 591, no. 6, pp. 1409-1432, 2013. 